\title{
Evidence that gonadotrophin surge-attenuating factor exists in man
}

\author{
I. E. Messinis* and A. A. Templeton \\ Department of Obstetrics and Gynaecology, University of Aberdeen, Foresterhill, \\ Aberdeen $A B 92 Z D, U K$
}

\begin{abstract}
Summary. This review article summarizes the evidence provided by in-vivo and in-vitro studies suggesting that the human ovary produces a nonsteroidal factor distinct from inhibin which participates in the control of gonadotrophin secretion from the pituitary.

This factor has been called gonadotrophin surge-attenuating factor ( $\mathrm{GnSAF})$ and is defined as attenuating the endogenous surge in luteinizing hormone $(\mathrm{LH})$ in superovulated women by reducing the pituitary response to $\mathrm{LH}$-releasing hormone. In-vivo bioactivity of GnSAF has been detected during the follicular phase of superovulated cycles; in-vitro studies have shown activity of this factor in human follicular fluid. From a physiological point of view, a hypothesis is proposed that GnSAF attenuates the amplitude of the positive effect of oestradiol on gonadotrophin secretion during the follicular phase of the human menstrual cycle and therefore plays an important role in controlling ovulation. If GnSAF is isolated, it may have several clinical applications including contraception.
\end{abstract}

Keywords: LHRH; LH; FSH; pituitary; GnSAF; man

\section{Introduction}

The control of gonadotrophin secretion in women is primarily achieved through ovarian secretion of steroids. However, during the past few years evidence has accumulated that the ovaries also produce nonsteroidal substances which affect the secretion of luteinizing hormone ( $\mathrm{LH})$ and follicle-stimulating hormone (FSH) from the pituitary. This may explain the pattern of gonadotrophin secretion in various physiological and abnormal conditions and may be important in clinical terms. Inhibin is such a substance, which has recently been identified and isolated as a glycoprotein hormone inhibiting gonadotrophin production and/or secretion from the pituitary, preferentially FSH (Burger \& Igarashi, 1988). Dimers of the subunits of inhibin, called activin, stimulate FSH secretion in vitro (Vale et al., 1986). The development of in-vitro fertilization techniques, in which multiple folliculogenesis is routinely induced, has provided new insights into the mechanisms which control the relationships between the ovaries and the hypothalamic-pituitary system (Messinis \& Templeton, 1988a). A new nonsteroidal factor has been recently detected in superovulated women that attenuates the endogenous LH surge in these patients through the reduction of the pituitary response to LH-releasing hormone (LHRH) and which we have named gonadotrophin surge-attenuating factor (GnSAF) (Messinis \& Templeton, 1989). It is not clear whether GnSAF is the same as or similar to a gonadotrophin surge-inhibiting factor (GnSIF) which has been assumed to block the endogenous LH surge in superovulated monkeys (Sopelak \& Hodgen, 1984).

*Author for correspondence: I. E. Messinis, Department of Obstetrics and Gynaecology, University of Ioannina, Ioannina, Greece. 


\section{Evidence from in-vivo studies}

\section{Midcycle LH surge}

The first evidence that a nonsteroidal ovarian factor is involved in the control of midcycle gonadotrophin secretion was from studies in monkeys. Superovulation induction in these animals with hMG or FSH inhibits positive feedback by oestradiol and blocks the endogenous $\mathrm{LH}$ surge (Hodgen, 1982; Schenken \& Hodgen, 1983). Blockage of the LH surge has also been reported in women during treatment with hMG for in-vitro fertilization (Ferraretti et al., 1983). Subsequent studies, however, in superovulated women have shown that an endogenous LH surge can occur, but this depends on the treatment regimen used for induction of multiple folliculogenesis. The endogenous LH surge always occurs when clomiphene is included in the regimen, but, occurs only in some women when only human gonadotrophins are used (Messinis et al., 1985, 1986a; Messinis \& Templeton, 1986). These results suggest that clomiphene facilitates the endogenous LH surge in superovulated women by blocking both the negative and positive feedback effects of oestradiol on the hypothalamic-pituitary system for a certain period (Messinis \& Templeton, 1988b). In that way, clomiphene induces an appropriately timed endogenous $\mathrm{LH}$ surge in relation to the size of the preovulatory follicle; in women treated only with gonadotrophins, the endogenous LH surge may be premature (Messinis \& Templeton, 1986; Templeton et al., 1986).

Another important regulator of the endogenous LH surge in women superovulated with FSH is the number of small, growing follicles in the ovaries. The more follicles, the higher the likelihood that LH surge will be postponed or blocked; the surge is more likely to be premature in the presence of a few such follicles (Messinis \& Templeton 1986, 1987a). These data suggest that the occurrence of the endogenous LH surge in FSH-superovulated women is the result of a balance between oestradiol and unspecified ovarian factors, secreted particularly by the small follicles.

When the endogenous LH surge occurs in superovulated women, it is markedly attenuated both in amplitude and duration and, in contrast to the occurrence, the attenuation of the surge is independent of the treatment regimen (Messinis et al., 1985, 1986a; Messinis \& Templeton, 1986). Inverse relationships between the amplitude of the $\mathrm{LH}$ surge and the total follicular fluid volume aspirated at laparoscopy in superovulated women have suggested that the putative factor responsible for the attenuation of the LH surge (GnSAF) is secreted by the hyperstimulated ovaries (Messinis et al., 1986b). High concentrations of serum oestradiol in women, induced after the administration of exogenous oestrogen, did not attenuate the midcycle LH surge during spontaneous menstrual cycles (Messinis \& Templeton, 1987b). Although supraphysiological concentrations of progesterone may reduce the duration of an LH surge induced by exogenous oestrogen (Messinis \& Templeton, 1990a), the endogenous LH surge in superovulated women is markedly attenuated, even in the presence of normal progesterone concentrations (Messinis \& Templeton, 1986). These studies provided some in-vivo evidence that GnSAF is nonsteroidal.

Inhibin is a well known nonsteroidal ovarian hormone, the concentration of which increases significantly in peripheral blood during superovulation induction (McLachlan et al., 1986; Tsonis et al., 1988). There are no studies in women to suggest that inhibin can suppress LH secretion either basally or during the midcycle LH surge. On the other hand, plasma concentrations of inhibin in superovulated women decrease significantly during the LH surge before they increase again during the luteal phase (Tsonis et al., 1988). It is probable, therefore, that inhibin does not play an important role in the attenuation of the LH surge in superovulated women.

\section{LH and FSH response to LHRH}

During superovulation induction with gonadotrophins, marked changes in the pituitary response to exogenous LHRH have been observed in animals and women. In rats, a blunted LH response to LHRH has been seen during FSH treatment (Geiger et al., 1980). Similarly, in 
monkeys, a blunted response of LH and FSH to pharmacological doses of LHRH has been reported during treatment with FSH or hMG (Schenken \& Hodgen, 1983; Littman \& Hodgen, 1984). The assumption was that GnSIF, a nonsteroidal substance produced by the ovaries, blocks the gonadotrophin response to LHRH and possibly the endogenous LH surge in superovulated monkeys (Sopelak \& Hodgen, 1984).

In women, superovulation induction with clomiphene or FSH results in a marked attenuation of gonadotrophin response to pharmacological doses of LHRH and this has been considered the mechanism of the attenuation of the endogenous LH surge in these patients (Messinis \& Templeton, 1989). The lack of oestrogenic effect during clomiphene administration and the unchanged concentrations of testosterone and progesterone in superovulated compared with spontaneous cycles provided further evidence that GnSAF is nonsteroidal (Messinis \& Templeton, 1989). Whether GnSAF and GnSIF are the same or similar factors is not clear. Obviously, species differences may occur, but, even if these two factors are similar, one has to consider from a physiologic perspective whether the factor's principal action is to block the LH surge or to control the amplitude of the surge.

Preliminary studies in women have investigated the in-vivo bioactivity of GnSAF and the mechanism of action on the hypothalamic-pituitary system. Using the response of the pituitary to LHRH as an in-vivo bioassay, activity of GnSAF has been detected in the mid- and late follicular phases of superovulated cycles, suggesting that GnSAF is produced at least by small growing follicles (Messinis \& Templeton, 1990c). The possibility that the decreased responsiveness of the pituitary to LHRH is related to a decrease in endogenous LHRH secretion seems to be excluded on the basis that administration of pulsatile LHRH to women in combination with FSH does not prevent the attenuation of the pituitary response to LHRH (Messinis \& Templeton, 1990b). Since the combination treatment in that study produced more follicles and a greater degree of attenuation, it is suggested that GnSAF exerts its effect at least at the pituitary level and that its activity increases with the degree of ovarian hyperstimulation. More recent data have shown that GnSAF attenuates both the LHRH-induced initial release of $\mathrm{LH}$ and the self-priming effect of LHRH on the pituitary (Messinis \& Templeton, in press). Whether this suggests an alteration of the availability of LHRH receptors on the gonadotrophs or a postreceptor site of action of GnSAF remains to be investigated.

\section{Evidence from in-vitro studies}

Studies in several species have investigated the effect of steroid-free follicular fluid on basal and LHRH-stimulated gonadotrophin secretion from pituitary cells in vitro, but have provided conflicting results (Lagace et al., 1979; Huang \& Miller, 1984; Danforth et al., 1987). This underlines the importance of species differences, although different experimental conditions may also be important. In one of these studies, pig follicular fluid reduced LHRH-stimulated LH release from rat pituitary cells in culture (Danforth et al., 1987). The nonsteroidal factor in pig follicular fluid inhibiting gonadotrophin secretion in that study was thought to be GnSIF, initially proposed for monkeys, although activity of this factor in monkey follicular fluid has not been reported. However, the gonadotrophin-inhibiting activity detected was different from inhibin (Danforth et al., 1987). An in-vitro bioassay, incorporating ovine pituitary cells in culture developed for the measurement of inhibin (Tsonis et al., 1986), has been used to assess bioactivity of GnSAF in human follicular fluid (Fowler et al., 1990a). Steroid-free human follicular fluid was able to suppress basal FSH but not LH secretion and reduce LHRH-stimulated release of LH and FSH. Although inhibin accounts for these effects on FSH secretion, it does not explain the attenuation of LHRH-induced LH release. Some suppression of LHRH-induced LH release from rat pituitary cells in vitro has been reported only after several days of incubation with purified bovine inhibin (Farnworth et al., 1988). Busbridge et al. (1990), however, demonstrated that purified bovine 
inhibin had no effect on LHRH-induced LH release in a pituitary perfusion system, but reduced LHRH-stimulated FSH secretion. In our ovine bioassay, after extraction of inhibin using heparin/ sepharose affinity chromatography (Danforth et al., 1987), human follicular fluid was able to attenuate the LHRH-induced $\mathbf{L H}$ and FSH release without affecting basal gonadotrophin secretion (Fowler et al., 1990a). These results suggest that GnSAF is present in human follicular fluid and is different from inhibin. Similar results were obtained in another study using rat pituitary fragments in a perfusion system (Knight et al., 1990). In that study, inhibin content in human follicular fluid was depleted using an immunoaffinity column. The possibility that different treatment regimens stimulate the secretion of ovarian factors, not normally produced in natural cycles, is unlikely, since attenuation of LHRH-induced LH secretion in vitro has been shown with human follicular fluid from women during an untreated spontaneous cycle (Busbridge et al., 1990).

A more recent study has shown greater activity of GnSAF in the follicular fluid of small than in large Graafian follicles in superovulated women (Fowler et al., 1990b). It is not clear, however, whether greater activity is the result of more rapid production of GnSAF by the smaller follicles. If this is the case, this contrasts with inhibin production, which is mainly by granulosa cells of preovulatory follicles (Hillier et al., 1989).

GnSAF is resistant to moderate heating, removed by dialysis of human follicular fluid and partly recovered in the dialysing fluid (Knight et al., 1990). Although a low molecular weight for the active factor has been postulated (Knight et al., 1990), our preliminary data using gel filtration chromatography have suggested a molecular weight between 70000 and 100000 (P. A. Fowler, I. E. Messinis \& A. A. Templeton, unpublished data).

\section{Comments}

These in-vivo and in-vitro studies have provided clear evidence that the human ovary produces GnSAF. We define GnSAF as a nonsteroidal factor distinct from inhibin, which attenuates the endogenous LH surge in women through the reduction of the pituitary response to LHRH. Although the activity of GnSAF is particularly evident during superovulation induction, its physiological importance during the human menstrual cycle is still a matter of conjecture. Before a hypothesis is put forward, two points require further discussion.

The first point is related to the blockage and attenuation of the LH surge in superovulated women. It is not clear whether these two events are different aspects of a single process or entirely separate. One would assume that blockage of the LH surge is the result of extreme suppression of gonadotrophin synthesis and/or release by GnSAF. This possibility, however, does not explain the constant occurrence of an endogenous LH surge when clomiphene is included in the treatment regimen (Messinis et al., 1985, 1986a,b). The fact that basal gonadotrophin values, particularly LH, are significantly greater than normal during clomiphene treatment and markedly suppressed during treatment with FSH (Messinis \& Templeton, 1988b, 1989) suggests that suppression of basal gonadotrophin secretion may be a prerequisite for the inhibition of the LH surge. It is likely, therefore, that GnSAF in superovulated cycles is primarily responsible for the attenuation of the LH surge, but, if basal gonadotrophin concentrations are also suppressed, depending on the degree of ovarian hyperstimulation, a marked attenuation of gonadotrophin response to LHRH may result in blockage of the surge.

If GnSAF had an inhibitory effect on the oestradiol-mediated positive feedback of gonadotrophin secretion during the early and midfollicular phases of the normal menstrual cycle, the aim would be to prevent early onset of the endogenous LH surge. In other words, if GnSAF activity could be eliminated during these stages of the cycle, the LH surge would occur in the presence of low concentrations of oestradiol. This hypothesis, however, is not true, because an LH surge occurs in the early and midfollicular phases of the normal menstrual cycle as long as preovulatory concentrations of oestradiol are achieved for a critical period (Liu \& Yen, 1983; Messinis \& Templeton, 
1990a). However, this surge is attenuated compared with that at midcycle (Liu \& Yen, 1983; Messinis \& Templeton, 1990a). The same criteria, in terms of serum oestradiol concentrations and the duration of pituitary exposure, also apply to postmenopausal women in whom the augmentation of the oestradiol-induced LH surge by exogenous progesterone is even greater (Liu \& Yen, 1983). It is clear, therefore, that GnSAF during the human menstrual cycle cannot be considered as preventing the oestradiol-positive effect and inhibiting the LH surge, but as regulating the amplitude of the surge by a negative effect. If GnSAF has any blocking effects on the LH surge, this occurs only under nonphysiological conditions, such as ovarian hyperstimulation, provided that basal gonadotrophin secretion is also suppressed.

The second point that merits further discussion is the role of small growing follicles. The greater GnSAF activity associated with small follicles (Fowler et al., 1990b) could indicate greater circulatory activity of this factor during the early follicular phase of the cycle, which decreases during the mid- and late follicular phases and particularly during the preovulatory period. In superovulated cycles, the number of small follicles increases dramatically through the continuous recruitment of new follicles by the high concentrations of FSH (Messinis \& Templeton, 1987a); an increase in the activity of GnSAF is suspected under these circumstances (Messinis \& Templeton, 1990c).

\section{Hypothesis}

Considering all these aspects, the following hypothesis, regarding the importance of GnSAF for gonadotrophin secretion during the human menstrual cycle, is proposed. In the early follicular phase, GnSAF maintains the pituitary in a state of low responsiveness to LHRH. As the follicle grows during the mid- and late follicular phases, GnSAF activity decreases and this facilitates the sensitizing effect of the rising oestradiol concentration on the pituitary gonadotrophs. When oestradiol exceeds the threshold concentration for the positive feedback effect during the preovulatory period, a marked drop in the activity of GnSAF occurs, resulting in a maximal response of the pituitary to oestradiol and a full expression of the midcycle LH surge.

According to this hypothesis, the primary action of GnSAF during the follicular phase of the human menstrual cycle is to control gonadotrophin response to hypothalamic LHRH by a negative effect and therefore to prevent maximal gonadotrophin secretion when it is not required. In that way, GnSAF does not inhibit the oestradiol positive feedback effect, but regulates the amplitude of gonadotrophin response to this stimulus and therefore plays a key role in controlling ovulation. In superovulated cycles, the high number of small follicles results in excessive production of GnSAF during the follicular phase, which attenuates the endogenous LH surge. In clinical terms, this hypothesis could explain the increased responsiveness of the pituitary to LHRH in postmenopausal women and in some pathological conditions such as the polycystic ovary syndrome. Identification and isolation of GnSAF may provide new means for the treatment of infertility and the development of contraceptive techniques.

The in-vitro preliminary experiments on GnSAF molecular weight (unpublished data) were performed by Dr P. A. Fowler. The secretarial assistance of Mrs S. Mearns is kindly acknowledged.

\section{References}

Burger, H.B. \& Igarashi, M. (1988) Inhibin-definition and nomenclature. $J$. clin. Endocr. Metab. 66, $885-886$.

Busbridge, N. J., Chamberlain, G.V.P., Griffiths, A. \& Whitehead, S.A. (1990) Non-steroidal follicular factors attenuate the self-priming action of gonadotrophin-releasing hormone on the pituitary gonadotroph. Neuroendocrinology 51, 493-499.
Danforth, D.R., Sinosich, M.J., Anderson, T.L., Cheng, C.Y., Bardin, C.W. \& Hodgen, G.D. (1987) Identification of gonadotropin surge-inhibiting factor (GnSIF) in follicular fluid and its differentiation from inhibin. Biol. Reprod. 37, 1075-1082.

Farnworth, P.G., Robertson, D.M., de Kretser, D.M. \& Burger, H.G. (1988) The effects of $31 \mathrm{kDa}$ bovine inhibin on FSH and $\mathrm{LH}$ in rat pituitary cells in vitro: 
antagonisms of $\mathrm{GnRH}$ and buserelin. J. Endocr. 119, 233-241.

Ferraretti, A.P., Garcia, J.E., Acosta, A.A. \& Jones, G. (1983) Serum luteinizing hormone during ovulation induction with human menopausal gonadotrophin for in vitro fertilization in normally menstruating women. Fert. Steril. 40, 742-747.

Fowler, P.A., Messinis, I.E. \& Templeton, A.A. (1990a) Inhibition of LHRH-induced $\mathrm{LH}$ and FSH release by gonadotrophin surge-attenuating factor (GnSAF) from human follicular fiuid. J. Reprod. Fert. 90, 587-594.

Fowler, P.A., Messinis, I.E. \& Templeton, A.A. (1990b) Gonadotrophin surge-attenuating factor (GnSAF) is produced preferentially by small follicles in superovulated women. J. Reprod. Fert. Abstr. Ser. 5, 8.

Geiger, J.M., Plas-Roser, S. \& Aron, Cl. (1980) Mechanisms of ovulation in female rats treated with $\mathrm{FSH}$ at the beginning of the estrous cycle; changes in pituitary responsiveness to luteinizing hormone releasing hormone (LHRH). Biol. Reprod. 22, 837-845.

Hillier, S.G., Wickings, E.J., Saunders, P.T.K., Dixson, A.F., Shimasaki, S., Swanston, I.A., Reichert, L.E. Jr. \& McNeilly, A.S. (1989) Control of inhibin production by primate granulosa cells. J. Endocr. 123, 65-73.

Hodgen, G.D. (1982) The dominant ovarian follicle. Fert. Steril. 38, 281-300.

Huang, E.S.R. \& Miller, W.L. (1984) Porcine ovarian inhibin preparations sensitize cultured ovine gonadotropes to luteinizing hormone-releasing hormone. Endocrinology 115, 513-519.

Knight, P.G., Lacey, M., Peter, J.L.T. \& Whitehead, S.A. (1990) Demonstration of a nonsteroidal factor in human follicular fluid that attenuates the selfpriming action of gonadotrophin-releasing hormone on pituitary gonadotropes. Biol. Reprod. 42, 613-618.

Lagace, L., Labrie, F., Lorenzen, J., Schwartz, N.B. \& Channing, C.P. (1979) Selective inhibitory effect of porcine follicular fluid on follicle stimulating hormone secretion in anterior pituitary cells in culture. Clin. Endocr. 10, 401-405.

Littman, B.A. \& Hodgen, G.D. (1984) Human menopausal gonadotrophin stimulation in monkeys: blockade of the luteinizing hormone surge by a highly transient ovarian factor. Fert. Steril. 41, 440446.

Liu, J.H. \& Yen, S.S.C. (1983) Induction of midcycle gonadotrophin surge by ovarian steroids in women: A critical evaluation. J. clin. Endocr. Metab. 57, 797-802.

McLachlan, R.I., Robertson, D.M., Healy, D.L., de Kretser, D.M. \& Burger, H.G. (1986) Plasma inhibin levels during gonadotrophin-induced ovarian hyperstimulation for IVF: A new index of follicular function? Lancet i, 1233-1234.

Messinis, I.E. \& Templeton, A. (1986) The effect of pulsatile follicle stimulating hormone on the endogenous luteinizing hormone surge in women. Clin. Endocr. 25, 633-640.

Messinis, I.E. \& Templeton, A.A. (1987a) Endocrine and follicle characteristics of cycles with and without endogenous luteinizing hormone surges during superovulation induction with pulsatile follicle-stimulating hormone. Hum. Reprod. 2, 11-16.
Messinis, I.E. \& Templeton, A.A. (1987b) Effect of high dose exogenous oestrogen on midcycle luteinizing hormone surge in human spontaneous cycles. Clin. Endocr. 27, 453-459.

Messinis, I.E. \& Templeton, A.A. (1988a) The endocrine consequences of multiple folliculogenesis. J. Reprod. Fert. Suppl. 36, 27-37.

Messinis, I.E. \& Templeton, A.A. (1988b) Blockage of the positive feedback effect of oestradiol during prolonged administration of clomiphene citrate to normal women. Clin. Endocr. 29, 509-516.

Messinis, I.E. \& Templeton, A.A. (1989) Pituitary response to exogenous $\mathrm{LHRH}$ in superovulated women. J. Reprod. Fert. 87, 633-639.

Messinis, I.E. \& Templeton, A.A. (1990a) Effects of supraphysiological concentrations of progesterone on the characteristics of the oestradiol-induced gonadotrophin surge in women. J. Reprod. Fert. 88, $513-519$

Messinis, I.E. \& Templeton, A.A. (1990b) Superovulation induction in women suppresses luteinizing hormone secretion at the pituitary level. Clin. Endocr. 32, $107-114$

Messinis, I.E. \& Templeton, A.A. (1990c) In-vivo bioactivity of gonadotrophin surge attenuating factor (GnSAF) Clin. Endocr. 33, 213-218.

Messinis, I.E. \& Templeton, A.A. (in press) Attenuation of gonadotrophin release and reserve in superovulated women by gonadotrophin surge attenuating factor (GnSAF). Clin. Endocr.

Messinis, I.E., Templeton, A. \& Baird, D.T. (1985) Endogenous luteinizing hormone surge during superovulation induction with sequential use of clomiphene citrate and pulsatile human menopausal gonadotropin. J. clin. Endocr. Metab. 61, 1076-1080.

Messinis, I.E., Templeton, A. \& Baird, D.T. (1986a) Endogenous luteinizing hormone surge in women during induction of multiple follicular development with pulsatile follicle stimulating hormone. Clin. Endocr. 24, 193 201.

Messinis, I.E., Templeton, A. \& Baird, D.T. (1986b) Relationships between the characteristics of endogenous luteinizing hormone surge and the degree of ovarian hyperstimulation during superovulation induction in women. Clin. Endocr. 25, 393-400.

Schenken, R.S. \& Hodgen, G.D. (1983) Folliclestimulating hormone induced ovarian hyperstimulation in monkeys: blockade of the luteinizing hormone surge. J. clin. Endocr. Metab. 57, 50-55.

Sopelak, V.M. \& Hodgen, G.D. (1984) Blockade of the estrogen-induced luteinizing hormone surge in monkeys: a nonsteroidal antigenic factor in porcine follicular fluid. Ferı. Steril. 41, 108-113.

Templeton, A., Messinis, I.E. \& Baird, D.T. (1986) Characteristics of ovarian follicles in spontaneous and stimulated cycles in which there was an endogenous luteinizing hormone surge. Fert. Steril. 46, 1113-1117.

Tsonis, C.G., McNeilly, A.S. \& Baird, D.T. (1986) Measurement of exogenous and endogenous inhibin in sheep serum using a new and extremely sensitive bioassay for inhibin based on inhibition of ovine pituitary FSH secretion in vitro. J. Endocr. 110, 341-352. 
Tsonis, C.G., Messinis, I.E., Templeton, A.A., McNeilly A.S. \& Baird, D.T. (1988) Gonadotropic stimulation of inhibin secretion by the human ovary during the follicular and early luteal phase of the cycle. J. clin. Endocr. Metab. 66,915-921.
Vale, W., Rivier, J., Vaughan, J., McClintock, R., Corrigan, A., Woo, W., Karr, D. \& Spiess, J. (1986). Purification and characterization of an FSH releasing protein from porcine ovarian follicular fluid. Nature, Lond. 321, 776-779.

Received 16 August 1990 